\title{
O PRÍNCIPE DO BRASIL: O PROBLEMA DAS DESCRIÇÕES DEFINIDAS ILUSTRADO
}

\section{O PRÍNCIPE DO BRASIL: AN ILLUSTRATION FOR THE PROBLEM OF DEFINITE DESCRIPTIONS}

\author{
Luana de Conto* \\ Unespar
}

Resumo: Neste artigo, analisamos o seguinte proferimento de Gregório Duvivier em seu twitter: “É fake que o príncipe fez suruba gay e bateu em mendigo. Ele não é príncipe.”. Essa sentença coloca um problema intrigante para análise porque contém a descrição definida o príncipe, que remete a um problema clássico da filosofia da linguagem: o problema da denotação de expressões que têm sentido, mas não têm referência. Russell (1905), que primeiro apontou esse problema, estabelece que descrições definidas como essa carregam a informação de que há um único príncipe do Brasil, e a inexistência de um indivíduo que satisfaça essa propriedade tornaria a sentença falsa. Strawson (1950) argumenta que isso se converte em condições de felicidade da sentença, na medida que essa informação faria parte do conteúdo pressuposto e não do conteúdo assertado. Por consequência, mostramos que o comentário de Gregório manipula essa pressuposição de existência através de negação metalinguística (HORN, 2001 [1989]), mas sem cancelá-la por completo, porque sua retificação se dirige apenas para o predicado da descrição definida e não para o quantificador existencial. Em consequência disso, o comentário de Gregório preserva a informação da asserção de que o indivíduo em questão participou de suruba gay e bateu em mendigo e pragmaticamente os interlocutores vinculam esse indivíduo ao deputado Luiz Phillipe de Orleans e Bragança, o pretenso príncipe. Assim, a análise demonstra princípios elementares de semântica e pragmática a partir de um dado extraído de uma interação real.

Palavras-chave: Semântica. Descrição definida. Negação metalinguística. Pressuposição.

Abstract: This paper presents a semantic analysis for a tweet published by Gregório Duvivier, which reads: "É fake que o príncipe fez suruba gay e bateu em mendigo. Ele não é príncipe.” 'It is false that the prince has joined a gay gangbang and beated a tramp'. This utterance bears a famous puzzle in the field of Philosophy of Language, for it contains a definite description (o príncipe - 'the prince'). Sentences like this are known from Russell's paper On denoting (1905), since they can have sense but still lack reference. This author highlights that definite descriptions convey the information that there is one and only one prince of Brazil, and the inexistence of such an individual would render this sentence false. Strawson (1950), on the other hand, believes this sentence would not be false, but invalid, because a lack of reference would affect the existence presupposition triggered by the definite description. Since it is part of the implicita and not part of the asserted information of the proposition, the lack of reference concerns the felicity conditions of the utterance. As a consequence, we claim that the tweet under analysis manipulates the existence presupposition by metalinguistic negation (HORN, 2001 [1989]) without cancelling it, because the retification is driven just to the predicate inside the definite description and not

* Doutora em Letras. E-mail: luana.conto@gmail.com. 
to the existential quantifier. For that reason, Gregorio's observation preserves the information that this individual has participated in the events of the main clause but the identification of such an individual by the hearer is done by pragmatic means, through extralinguistic knowledge. Thus, this analysis demonstrates how elementary principles both from Semantics and Pragmatics work, building them from a sentence extracted from real speech interaction.

Keywords: Semantics. Definite descriptions. Metalinguistic negation. Presupposition.

\section{INTRODUÇÃO}

Este artigo apresenta a aplicação e discussão dos conceitos de descrições definidas, pressuposição e negação metalinguística, a partir da perspectiva da Semântica Formal. Para tanto, ilustra-se a análise de um dado contendo uma descrição definida, publicado em rede social. Na primeira seção, são apresentados o dado e o contexto em que ele se insere, para mapear o quadro de informações compartilhadas pelos interlocutores que lhes permite o cálculo do significado. Esse dado se assemelha em muito a uma sentença clássica da filosofia da linguagem: "O rei da França é calvo”; por isso, traz-se para a discussão alguns autores que foram cruciais para os estudos desse tema. Na segunda e na terceira seções, discute-se o problema da descrição definida, que contempla existência e unicidade do referente, a partir da discussão proposta por Russel (1905) e sua revisão por Strawson (1950). As consequências da negação da descrição definida são apresentadas na quarta seção, com especial atenção para a negação metalinguística, conforme Horn (2001 [1989]). A quinta seção finaliza a análise, discutindo como se dá a correferenciação entre o pronome e a descrição definida, presentes no dado de análise, e explicitando os movimentos argumentativos do autor do comentário. Por fim, as considerações finais apontam para méritos e desdobramentos da análise apresentada.

\section{O DADO EM ANÁLISE}

Em 13 de novembro de 2019, Gregório Duvivier publica em sua conta pessoal de uma rede social a seguinte afirmação: “atenção: é fake que o príncipe fez suruba gay e bateu em mendigo. ele não é príncipe. repassem”.

Figura 1: Publicação em rede social.

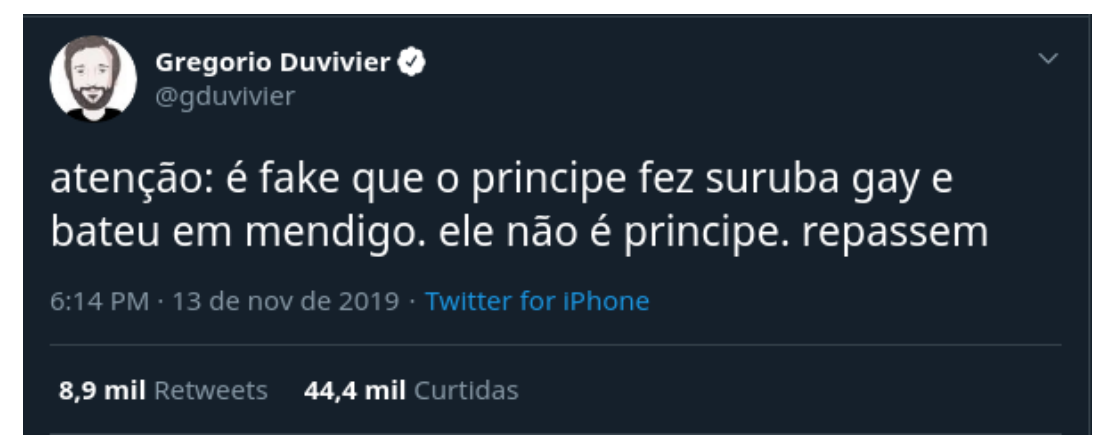

Fonte: Disponível em: https://twitter.com/gduvivier/status/1194725247670505473. Acesso em: 28 nov. 2020. 
O tweet do Gregório foi publicado em um momento em que o deputado Luiz Phillipe de Orleans e Bragança veio a público, em entrevista à revista Crusoé, para declarar que Bolsonaro havia se desculpado por ter desistido de convidá-lo para a vice-presidência. A desistência teria ocorrido em virtude de um dossiê apresentado por Gustavo Bebianno que conteria imagens do deputado participando de uma orgia gay e agredindo moradores de rua. $\mathrm{O}$ deputado negou a veracidade das imagens e afirmou que não é gay.

As manchetes que circularam a respeito do fato já ilustram o problema que permeia nossa análise:

(1) Príncipe diz que acusação de suruba gay o impediu de ser vice de Bolsonaro. ${ }^{1}$

(2) 'Príncipe’ confirma dossiê e diz que Bolsonaro o descartou com base em armação.'

(3) Bebianno apresentou fotos de ‘suruba gay’ para impedir que eu fosse vice, diz 'príncipe’. 3

(4) “Nem sei onde faz suruba gay”, diz 'príncipe’ Luiz Phillipe de Orleans sobre boato espalhado por Frota. ${ }^{4}$

Enquanto a manchete da Carta Capital (1) assume o termo príncipe como designador de Luiz Phillipe de Orleans e Bragança, Época (3) e Istoé (4) acompanham a Revista Crusoé (2) na hesitação do emprego desse termo e preferem marcá-lo com aspas, assinalando uma certa alienação da designação. O UOL esclarece textualmente a desconfiança sem, no entanto, questionar a legitimidade do emprego do termo família imperial do Brasil: "O deputado Luiz Phillipe de Orleans e Bragança, conhecido como ‘príncipe’ por ser membro da família imperial do Brasil, [...]”. ${ }^{5}$ A problemática que se coloca, então, diz respeito ao referente de "O príncipe da família imperial do Brasil”. Essa expressão, que pode ocultar a modificação da família imperial do Brasil e ocorrer simplesmente como o príncipe, configura-se como uma descrição definida e, como tal, faz referência a um indivíduo único no mundo. No entanto, dado o fato de que o Brasil não é uma monarquia, tampouco um império, o emprego do termo príncipe para designar um herdeiro de uma família que outrora teve um status monarca é controverso. É nesse espaço que o comentário de Gregório Duvivier se situa e, por isso, a denotação das descrições definidas se mostra relevante para entender o processo de construção de sentidos desse tweet.

Na próxima sessão, aprofundamos esse conceito e apresentamos a discussão que o rodeia.

\section{DESCRIÇÕES DEFINIDAS}

Para Frege (2009 [1892], p. 131-132), as descrições definidas se comportam como nomes próprios (termo que aqui adquire uma cobertura mais ampla do que na perspectiva da gramática

\footnotetext{
${ }^{1}$ Disponível em: https://www.cartacapital.com.br/politica/principe-diz-que-acusacao-de-suruba-gay-o-impediu-de-ser-vice-debolsonaro/. Acesso em: 12 jun. 2020.

${ }^{2}$ Disponível em: https://crusoe.com.br/diario/principe-confirma-dossie-e-diz-que-bolsonaro-o-descartou-com-base-em-armacao/. Acesso em: 12 jun. 2020.

${ }^{3}$ Disponível em: https://epoca.globo.com/bebianno-apresentou-fotos-de-suruba-gay-para-impedir-que-eu-fosse-vice-dizprincipe-1-24078935. Acesso em: 12 jun. 2020.

${ }^{4}$ Disponível em: https://istoe.com.br/luiz-philippe-diz-que-dossie-o-tirou-da-vice-presidencia/. Acesso em: 12 jun. 2020.

${ }^{5}$ Disponível em: https://noticias.uol.com.br/politica/ultimas-noticias/2019/11/13/principe-bebianno-mostrou-suruba-gay-para-eunao-ser-vice-de-bolsonaro.htm. Acesso em: 12 jun. 2020.
} 
tradicional), na medida que podem igualmente fazer referência a um objeto determinado, e não a um conceito. Lembremos que Frege (2009 [1892]) havia partido de descrições definidas para explicitar sua teoria sobre sentido e referência. $\mathrm{O}$ autor chamou a atenção para cópulas identificadoras, ${ }^{6}$ como a seguinte:

(5) A estrela da manhã é a estrela da tarde.

Por meio dessa sentença, Frege demonstra que as duas expressões, a estrela da manhã e a estrela da tarde, têm a mesma referência - o planeta Vênus -, ainda que o sentido de cada uma dessas expressões seja diferente. Apesar de não serem o próprio nome do planeta em questão, a construção linguística de cada uma dessas expressões é capaz de delimitar um referente determinado no mundo, por conta da propriedade da definitude.

Dentre outras configurações estruturais possíveis, descrições definidas podem ser formadas a partir combinação entre um artigo definido e um predicado, como [o [professor de linguística]] ou [o [aluno que tirou dez na prova]]. O predicado professor de linguística, por exemplo, pode figurar em uma sentença copular e denota um conjunto de indivíduos que compartilham a propriedade em questão. Por exemplo, em (6), essa expressão é um predicado que se aplica a Borges Neto, por intermédio da cópula predicativa:

(6) Borges Neto é professor de História da Linguística.

(7) Borges Neto é humano.

A interpretação dessa sentença atribui uma propriedade ao referente de nome próprio Borges Neto, na medida que a proposição afirma que ele é membro do conjunto dos professores de História da Linguística. Portanto, a predicação de ser professor de Linguística se assemelha a uma predicação como ser humano em (7), já que ambas asseguram que esse indivíduo faz parte da denotação do conjunto do respectivo predicado.

No entanto, a presença do artigo o dá outra interpretação para a cópula e para o predicativo dessa sentença, como se observa em (8):

(8) Borges Neto é o professor de História da Linguística.

A diferença entre (6) e (8) é que (8) evoca a existência de uma vaga de professor de História da Linguística e também uma unicidade, já que constrói a expectativa de que haja uma vaga só de professor de História da Linguística. O que essa sentença informa é basicamente isso, que há uma única vaga de professor de História da Linguística e que ela foi preenchida por Borges Neto. Esse direcionamento para a unicidade não se observa em (6), porque, neste caso, é possível vislumbrar a existência de outros professores de História da Linguística, isto é, outros membros do conjunto denotado pelo predicado ser professor de História da Linguística.

A questão é que (6) apresenta essa expressão como um predicado e, enquanto predicado, não se manifesta sobre a cardinalidade do conjunto, isto é, o predicado veicula a propriedade necessária para que um item se torne membro do seu conjunto, mas não tem nada a dizer a

${ }^{6}$ Para uma compreensão mais acurada das diferenças entre a cópula predicativa e a cópula identificadora, referimos o leitor a Raposo (2013, p. 1318-1319), em que se traça uma diferenciação entre cópulas caracterizadoras e cópulas identificadoras. 
respeito da natureza do conjunto resultante dessa denotação. Predicados denotam conjuntos porque são expressões insaturadas, funções. Já descrições definidas são expressões saturadas e referenciais.

O que a definitude do determinante $o$ faz em (8) é justamente operar sobre o conjunto denotado pelo predicado, neste caso determinando que há apenas um membro dentro dele. ${ }^{7}$

É importante observar aqui que a cópula em (8) é uma cópula identificadora porque coloca em relação de igualdade duas expressões, justamente porque elas apontam para o mesmo referente no mundo. Borges Neto levará à referência de um indivíduo X no mundo (no caso deste mundo real em que habitamos, um senhor de barba grisalha e uma pancinha carismática, admirador da cultura portuguesa), da mesma forma que o professor de História da Linguística também se refere ao mesmo indivíduo X (neste mesmo mundo real, o senhor de barba grisalha e pancinha carismática, admirador da cultura portuguesa).

A ideia de que definitude se vincula a unicidade remonta à análise de Russell (1905, p. 481) sobre as descrições definidas. Russell (1905) questiona Frege ao afirmar que denotar não é significar, porque (9) tem um significado, apesar de sua denotação não levar a uma referência. Examinemos a sentença em questão.

(9) O rei da França é calvo.

Considerando que o estado da França é uma república e não uma monarquia, a sentença (9) seria falsa para Russell. O autor explica que não é possível encontrar um referente mapeado pela expressão “o rei da França” - ninguém é rei da França se a França não é uma monarquia - e assim não haveria um tal indivíduo presente no conjunto que denota as coisas que são calvas, provando a sentença como falsa.

A sentença em (9) recebe a seguinte interpretação semântica:

$$
\text { (10) } \exists \mathrm{x}(\mathrm{Kx} \wedge \forall \mathrm{y}(\mathrm{Ky} \rightarrow \mathrm{x}=\mathrm{y}) \wedge \mathrm{Bx})
$$

A fórmula acima expressa não apenas que existe um indivíduo que é rei da França $(K x)$ e que ele é careca $(B x)$, mas também que, para todo indivíduo y, se esse indivíduo satisfaz a propriedade de ser rei da França, então ele é idêntico ao indivíduo x $(\forall y(K y \rightarrow x=y)){ }^{8}$ Essa parte da expressão, especificamente, garante que não haja mais de um indivíduo que seja rei da França, porque condiciona, a partir da implicação, que todo indivíduo rei da França seja idêntico ao indivíduo sobre o qual incide a predicação da sentença.

Perceba-se que, na formulação de Russell, a interpretação da sentença contendo uma descrição definida é resultado da conjunção $(\Lambda)$ de três informações:

\footnotetext{
${ }^{7}$ Há também uma discussão sobre a propriedade de familiaridade, que indicaria que o referente já é de conhecimento dos interlocutores por conhecimento de mundo ou por informação prévia discursiva. Essa propriedade é de grande relevância para os usos anafóricos do artigo definido. Para a análise das descrições definidas, deixamos de lado a discussão sobre familiaridade.

${ }^{8}$ Lewis (1979, p. 348) descarta a pressuposição de unicidade das descrições definidas em favor da saliência discursiva. A saliência discursiva é uma propriedade interessante associada à definitude e explica por que podemos usar a expressão o príncipe em lugar de o príncipe da família imperial do Brasil. No entanto, não exploraremos a fundo os desdobramentos da análise de Lewis, por questão de espaço.
} 
(11) Existe um indivíduo que é rei da França;

\& esse indivíduo é o único rei da França;

\& esse indivíduo é careca.

Por consequência da conjunção, para que essa sentença seja verdadeira, é necessário que todas as três condições sejam satisfeitas. Pela análise de Russell, se não há um rei da França, a sentença (9) será falsa; se houver mais de um rei da França, essa sentença será falsa; se o rei da França não for careca, essa sentença será falsa.

É razoavelmente trivial a relação entre a análise de Russell e a discussão do caso do Deputado Luiz Phillipe de Orleans e Bragança. Partimos da afirmação em (12).

(12) O príncipe [do Brasil] fez suruba gay e bateu em mendigo.

Para que essa afirmação seja verdadeira, é necessário que sejam satisfeitas todas essas condições:

(12’) Existe um indivíduo que é príncipe do Brasil

\& esse indivíduo é o único príncipe do Brasil

\& esse indivíduo fez suruba gay

\& esse indivíduo bateu em mendigo.

A sentença em (12) será falsa sempre que qualquer uma das afirmações de (12’) se provarem falsas na verificação no mundo. Portanto, pela proposta de Russell, a sentença (12) pode ser falsa pelo motivo de que (i) o evento de fazer suruba não se verifique, ou que (ii) o evento de bater em mendigo não se verifique, ou que (iii) não exista um príncipe do Brasil, ou que (iv) haja mais de um príncipe do Brasil. A argumentação do deputado se apoia na negação dos motivos apresentados em (i) e (ii). A argumentação de Gregório Duvivier, por outro lado, mobiliza o motivo em (iii), mas não se limita a isso. Como veremos a seguir, o movimento argumentativo do humorista é mais complexo do que isso porque implica a afirmação dos eventos de (i) e (ii), o que não seria possível se fosse assumida a falsidade trivial da proposição de (12) - isso porque uma proposição é falsa por completo, não pode ser falsificada apenas em parte.

Como veremos a seguir, essa problemática acompanha as limitações que o próprio raciocínio de Russell encontrou no desenrolar da análise formal das descrições definidas.

\section{A PRESSUPOSIÇÃO}

A representação de Russell (1905) da premissa de existência e de unicidade por meio da estrutura de conjunção foi questionada por Strawson (1950), especialmente porque a frustração dessas premissas leva, na teoria de Russell, à falsidade da sentença. Essa falsidade seria uma consequência forte demais para a descrição do que ocorre quando não é possível mapear o referente de uma descrição definida.

Strawson (1950, p. 330) sugere que, ao contrário do que sustenta Russell, sentenças contendo descrições definidas sem referencial no mundo não são falsas. Isso não significa que 
elas sejam verdadeiras. Elas seriam sentenças inválidas, porque a questão da veracidade ou falsidade não se coloca, uma vez que não é possível saber de quem essa sentença trata. Dessa forma, sentenças como (8) não são suscetíveis nem mesmo a uma verificação de veracidade no mundo, justamente em decorrência da impossibilidade de mapeamento do referente. Essa postura tem como consequência uma lógica não dual de valores de verdade, uma lógica trivalorada - isto é, para que a teoria de Strawson funcione, é necessário assumir que as sentenças possam ou (i) ser verdadeiras, ou (ii) ser falsas, ou (iii) não ter valor de verdade atribuído. Essa é uma consequência bastante complexa para sistemas lógicos, e talvez seja o preço a se pagar quando se analisam proposições dentro de línguas naturais.

A principal motivação para Strawson abrir mão da atribuição de valor de verdade falso a sentenças com descrições definidas é a constatação de que a afirmação de (13b) juntamente a (13a) não gera uma contradição lógica.

(13a) O rei da França é sábio.

(13b) Não existe um rei da França.

(STRAWSON, 1950, p. 330)

O autor assinala que, diante da afirmação em (13a), a tendência do interlocutor é de apontar uma incoerência por parte do falante, algo como "Creio que você pode ter se enganado, porque não há um rei da França”, sugerindo que a afirmação de (13a) revele uma evidência de que o falante carregava uma crença falsa, sustentando sua afirmação em informações que se revelam inapropriadas. Dessa forma, (13b) sugere uma revisão no que é dado como certo quando da afirmação de (13a). Se a afirmação de que existe um rei da França fosse parte do conteúdo assertado em (13a), essas duas proposições deveriam formar uma contradição: em termos técnicos, não podem ser simultaneamente verdadeiras. Mas o que acontece é que, na verdade, não é possível assegurar nem a verdade nem a falsidade da primeira.

A justificativa para isso residiria no fato de que "referir não é assertar" (STRAWSON, 1950, p. 333). Perceba a diferença do diálogo em (14) para aquele presente em (13).

(14a) Existe um rei da França. Ele é sábio.

(14b) Não existe um rei da França.

Agora de fato a contradição entre as duas afirmações é inquestionável, porque, enquanto um falante afirma uma proposição ( $\mathrm{P}$ = 'existe um rei da França'), o interlocutor afirma o exato oposto ( $\neg \mathrm{P}=$ 'não existe um rei da França') e não há conciliação que permita que essas duas afirmações sejam simultaneamente verdadeiras. A diferença é que em (14a) a existência faz parte do conteúdo assertado: a existência é afirmada, por assim dizer. Em (13a), a existência advém da descrição definida o rei da França - a existência de um rei da França está vinculada ao significado dessa sentença, mas poderíamos dizer que é de uma maneira indireta, pois não é parte do conteúdo assertado.

O argumento de Strawson, então, é que as premissas de existência e unicidade são informações implicadas e, como tal, não são parte do conteúdo assertado pela proposição. Por consequência, a negação do conteúdo pressuposto não leva à falsificação da proposição assertada, apenas afeta as condições de felicidade do proferimento. Em outras palavras, a não existência 
de um rei da França não impede que a sentença veicule um significado, mas esse significado não é verdadeiro nem falso, é nonsense.

Então, o que na análise de Russell se colocava como duas condições necessárias para a veracidade da sentença, por conta da conjunção, na análise de Strawson se apresenta como duas pressuposições. A sentença em (9), retomada abaixo, apresentaria então essas duas camadas de significação:

(15) O rei da França é calvo.

a. Pressupõe que existe um rei da França e pressupõe que apenas um referente é rei da França;

b. Asserta que o indivíduo é calvo.

O conceito de pressuposição, essencial para essa análise, diz respeito a uma informação implícita, tomada como verdade, mas se distingue de um acarretamento. Enquanto o acarretamento se estabelece quando a veracidade de uma sentença assegura a veracidade de outra, a pressuposição é preservada mesmo diante da negação da sentença disparadora. Vejamos como o conceito tem sido formulado.

If A presuposes B, then A not only implies B but also implies that the truth of B is somehow taken for granted, or is treated as uncontroversial. The term pre-supposition reflects the idea that the implication is background information, already part of the knowledge shared by speaker and hearer when the presupposition carrying expression is uttered in the discourse (SWART, 1998, p. 35). ${ }^{9}$

A natureza da pressuposição não se limita ao cálculo lógico, uma vez que ela dá pistas sobre as informações presentes no fundo conversacional compartilhado pelos interlocutores. Diz-se também que ela é vinculada a determinadas expressões linguísticas, que disparam o reconhecimento de informações outras quando estão presentes em uma afirmação. São os chamados "gatilhos pressuposicionais", dentre os quais se encontram as descrições definidas (BEAVER; GEURTS, 2018).

Dado que o conteúdo pressuposto não é assertado, mas sim implícito, a pressuposição se mantém mesmo se houver uma alteração no valor de verdade da pressuposição. Por isso, o seu diagnóstico costuma ser feito a partir da constatação da preservação da pressuposição mediante a negação da sentença.

(16) O rei da França não é calvo.

Da mesma forma que (9), a sentença em (16) também pressupõe que existe um rei da França e que há um único rei da França. O que a distingue de (9) é apenas a negação, assegurando que, se (9) for verdadeira, (16) será falsa, e vice-versa. Portanto, as condições de verdade de cada uma dessas sentenças são diferentes, de modo que o conteúdo assertado é diferente.

\footnotetext{
9 “Se A pressupõe B, então A não apenas implica B, mas também implica que a verdade de B é de alguma forma tomada como certa ou tratada como incontroversa. O termo pressuposição reflete a ideia de que a implicação é uma informação de pano de fundo, parte do conhecimento compartilhado pelo falante e pelo ouvinte quando a expressão que carrega a pressuposição é proferida no discurso" (tradução minha).
} 
Veremos ainda, na próxima seção, mais detalhes sobre o papel importante desempenhado pela negação no cálculo do significado dessa sentença.

É comum se estender o teste de preservação da informação pressuposta a outras construções que também manipulam o valor de verdade da proposição, a saber, a interrogação e a subordinação condicional. Voltamos ao caso do deputado-príncipe para testar a família pressuposicional e verificar se a existência e a unicidade do príncipe é uma informação preservada. Vemos em (17) a afirmação da proposição, em (18) a negação da proposição, em (19) a interrogação da proposição e em (20) o condicional da proposição.

(17) O príncipe fez suruba gay e bateu em mendigo.

(18) O príncipe não fez suruba gay e bateu em mendigo.

(19) O príncipe fez suruba gay e bateu em mendigo?

(20) Se o príncipe fez suruba gay e bateu em mendigo, ele não deve ser vice-presidente.

A afirmação (17) é a própria proposição que estamos testando para checar se carrega uma pressuposição. Conseguimos a partir dela mapear a informação candidata a pressuposta: para interpretá-la, sabemos que os predicados se aplicam a um indivíduo, que é um príncipe e que se reconhece como o único príncipe desse contexto. Já (18) assinala exatamente o oposto disso: que os predicados não se aplicam a esse indivíduo, mas ainda partimos da identificação desse indivíduo como um príncipe, único no contexto. Da mesma forma, em (19) se indaga sobre a aplicação dos predicados, sem acessar a denotação desses conjuntos, mas partindo do reconhecimento do indivíduo indagado como príncipe e único. Em (20), por fim, o condicional direciona a verificação da aplicação das propriedades para mundos possíveis, mas também parte do mesmo caminho para identificação do indivíduo. Concluímos, portanto, que, para todas elas, a informação da existência e da unicidade do príncipe se preserva independentemente da mudança ou suspensão do valor de verdade da proposição, em consonância com a literatura sobre descrições definidas, o que permite concluir que essa informação não é parte das condições de verdade da proposição, mas parte do conteúdo pressuposto como conhecimento compartilhado pelos interlocutores.

(21) O príncipe fez suruba gay e bateu em mendigo.

a. Pressupõe que existe um príncipe (do Brasil) e pressupõe que apenas um referente é príncipe (do Brasil);

b. Asserta que o indivíduo fez suruba gay e que o indivíduo bateu em mendigo.

O comentário de Gregório emprega a negação da proposição, como veremos a seguir, e a partir disso manipula as camadas de informações pressupostas.

\section{NEGAÇÃO DE DESCRIÇÕES DEFINIDAS}

Russell (1905, p. 490) já chamava atenção para o fato de que sentenças com negação e descrições definidas resultam em ambiguidade, por conta do escopo da negação. Assim, a sentença (16), repetida em (22), tem duas possibilidades de interpretação. 
(22) O rei da França não é calvo.

(23) Existe um indivíduo x que é rei da França e x não é calvo.

(24) Não é o caso que existe um indivíduo que é rei da França e é calvo.

Na interpretação (23), a negação está sob o escopo do quantificador existencial e assim o que é negado é o predicado, como mencionamos na análise da família pressuposicional. Já na interpretação (24), é a negação que toma escopo sobre o quantificador existencial e nega-se inclusive a existência de um indivíduo que tenha a propriedade de ser rei da França. Essa diferença é capturada pelas respectivas representações semânticas:

(23’) Negação interna:

$$
\exists \mathrm{x}(\mathrm{Kx} \wedge \forall \mathrm{y}(\mathrm{Ky} \rightarrow \mathrm{x}=\mathrm{y}) \wedge \neg \mathrm{Bx})
$$

(24’) Negação externa:

$$
\neg \exists \mathrm{x}(\mathrm{Kx} \wedge \forall \mathrm{y}(\mathrm{Ky} \rightarrow \mathrm{x}=\mathrm{y}) \wedge \mathrm{Bx})
$$

(HORN, 2001 [1989], p. 106)

Horn (2001 [1989], p. 106) associa essa diferença de escopo a uma diferença terminológica entre negação interna e negação externa. A negação externa é assim chamada porque a posição da negação $(\neg)$ é capaz de abarcar todo o resto da proposição. Enquanto a prosódia de (22) associada à interpretação em (23) seria não marcada, a interpretação em (24) viria associada a uma prosódia marcada para (22), que sinaliza para o interlocutor um tipo diferente de negação. Essa negação é a chamada negação metalinguística e, além da prosódia contrastiva, ela também apresenta a retificação, ${ }^{10}$ que compreende a correção de determinado trecho de informação veiculado anteriormente pelo falante ou por seu interlocutor. Observe que em (25) a negação externa se torna mais saliente por conta da retificação.

(25) O rei da França não é `careca - (porque) não tem nenhum rei da França. (HORN, 2001 [1989], p. 362)

Como Horn (2001 [1989]) aponta, a negação metalinguística é “um recurso para objetar um proferimento anterior por qualquer motivo, inclusive objetar os implícitos convencionais ou conversacionais que sejam gerados por esse proferimento, sua morfologia, seu estilo ou registro, ou sua realização fonética” (HORN, 2001 [1989], p. 363, tradução minha). Em outras palavras, essa negação serve para corrigir ou discordar de algum elemento de um enunciado mencionado anteriormente em diferentes níveis linguísticos.

Como ilustração de negação metalinguística de implícitos, Horn relembra uma conhecida propaganda de veículo automotivo, e adicionamos ainda um comentário flagrante veiculado em um jornal de mídia televisiva.

(26) Não é um carro, é um Volskwagen.

\footnotetext{
${ }^{10}$ A negação metalinguística e a retificação são trabalhadas também por Ducrot, uma perspectiva que não abordaremos aqui. Além da prosódia e da retificação, Horn (2001 [1989], p. 368) aponta ainda que a negação metalinguística também tem a característica de não licenciar itens de polaridade negativa, que é uma propriedade elementar da negação trivial. Não discutiremos esse fenômeno aqui porque não há nenhum item de polaridade negativa no dado em análise.
} 
(27) Cidadão, não! Engenheiro civil, melhor do que você.

Nos dois casos, os nomes comuns carro e cidadão, por seu caráter generalista, disparam uma implicatura de ordinariedade: por ter uma denotação ampla, essas propriedades não trazem uma característica de destaque para os membros do conjunto, então um carro pode ser um carro qualquer e um cidadão pode ser um cidadão qualquer. É certo que a negação aplicada não pode se direcionar estritamente para o predicado, já que não se nega que o indivíduo em questão seja de fato um carro ou um cidadão, inclusive porque há uma relação de subconjunto aí: todos os membros do conjunto dos engenheiros civis são também membros do conjunto dos cidadãos. Por consequência, não se trata de uma negação trivial, mas sim de uma negação metalinguística, dirigida para a implicatura de ordinariedade: não se trata de um carro ou cidadão qualquer. E daí o termo escolhido para a retificação seleciona um subconjunto que dispara a implicatura de superioridade - um Volkswagen não seria um carro qualquer e um engenheiro civil não seria um cidadão qualquer.

No caso de (25), que contém a expressão definida o rei da França, a retificação é dirigida especificamente para o conteúdo implícito da pressuposição. Ao afirmar que não tem nenhum rei da França, o falante ajusta o escopo da negação para a negação externa: não é o caso que existe um indivíduo que é rei da França e é calvo.

É essa também a estratégia do comentário de Gregório, que retomamos abaixo.

(28) É fake que o príncipe fez suruba gay e bateu em mendigo. Ele não é príncipe.

Consideremos que é fake que aqui tem o mesmo significado de é falso que/não é o caso que, expressando o operador da negação nas formulações lógicas costumeiras. É claro que o termo fake é empregado nesse contexto mantendo um diálogo com o contexto discursivo do momento, que põe em debate a circulação de fake news, e com o fato de o próprio deputado Luiz Phillipe de Orleans e Bragança estar acusando Gustavo Bebbiano de divulgar um boato falso. De qualquer maneira, o significado composicional de é fake que contribui para o cálculo da sentença com a negação da proposição “o príncipe fez suruba gay e bateu em mendigo”.

A posição inicial desse termo não garante a exclusividade da interpretação como negação externa, ou seja, levando em conta apenas a primeira sentença de (28), a ambiguidade se mantém. É com a presença de uma retificação na frase complementar que se segue, "ele não é príncipe”, que a negação metalinguística se torna saliente. Essa retificação se dirige para a pressuposição disparada pela descrição definida de que existe um príncipe (do Brasil) e que apenas um referente é [príncipe do Brasil], conforme (21a) acima. Só que precisamos discutir qual é o escopo dessa negação porque a retificação nega apenas o predicado que estava contido dentro da pressuposição existencial ( $x$ é príncipe do Brasil), já que não caberia ao referente de Luiz Phillipe de Orleans e Bragança a predicação de príncipe porque ele não é príncipe. Ressaltamos que o movimento de Gregório em (28) não implica na negação da existência por completo e voltaremos a este tópico na seção seguinte.

Antes disso, vale a pena acrescentar que, quando não há a retificação, a sentença continua ambígua e a negação pode ser interpretada de maneira trivial, o que acontece, por exemplo, no relato da entrevista de Luiz Phillipe de Orleans e Bragança, que pode ser parafraseado como (30). 
(29) O príncipe não fez suruba e não bateu em mendigo.

(30) É falso que o príncipe fez suruba e bateu em mendigo.

A interpretação consonante com a declaração dada pelo deputado é a da negação interna, em que ocorre a negação dos predicados e não do quantificador existencial, conforme (23) e (23’). Isso significa que, da perspectiva do deputado, a pressuposição se mantém e assim se toma como informação de background do fundo conversacional que existe um (único) príncipe do Brasil.

Do ponto de vista de Gregório Duvivier, no entanto, o que está em jogo é justamente a disputa sobre a pressuposição disparada pela descrição definida. Ao empregar a negação metalinguística, Gregório está justamente sinalizando sua indisposição em aceitar a totalidade das informações pressupostas como parte do fundo conversacional compartilhado.

\section{A AFIRMAÇÃO DO BOATO}

Afirmamos que a retificação de Gregório não implica na negação completa da pressuposição de existência por conta do fato de que o pronome ele encontra o seu referente na descrição definida o príncipe, por retomada anafórica.

Para descartar inicialmente a ancoragem dêitica do pronome, recuperamos a situação discursiva de onde o dado foi coletado. Veremos que o tweet foi publicado de forma independente - não é uma resposta (reply) nem um comentário de compartilhamento de outro tweet (retweet), de modo que não há nem a presença nem a menção explícita do deputado Luiz Phillipe de Orleans e Bragança. Por conta disso, descartamos a ancoragem dêitica como estratégia de indexação do pronome, porque não há um referente dêitico disponível, não há um item animado para o qual se apontar. ${ }^{11}$

Para que a retomada anafórica aconteça, é necessário que haja correferenciação entre ele e o príncipe, a descrição definida que está mais saliente no contexto. Se retomamos a diferença entre sentido e referência fregeana (FREGE, 2009 [1892], p. 131), a expressão o príncipe é o “modo de apresentação do objeto”, enquanto a referência seria o próprio ente designado pelo sinal linguístico. Assim, a referência de o príncipe seria o próprio indivíduo que atende pelo nome de Luiz Phillipe de Orleans e Bragança. E sabemos por conhecimento de mundo que é justamente esse o indivíduo que Gregório afirma não ser príncipe.

Se Gregório rejeitasse a pressuposição de existência, ele estaria abortando também a possibilidade de que a descrição definida o príncipe levasse ao referente de Luiz Phillipe de

\footnotetext{
${ }^{11}$ Há uma outra opção de indexação dêitica, que de certa forma poderia ser chamada de abstrata, que seria a ancoragem em um referente saliente discursivamente. O raciocínio seria o que se segue. Por mais que Gregório esteja verbalmente desqualificando o termo o príncipe como uma descrição pertinente para o deputado, a informação de que o deputado atribui a si mesmo essa descrição não foi descartada do universo discursivo compartilhado nessa situação comunicativa. Ela é acessada pelos falantes e, dentre todos os indivíduos igualmente disponíveis no contexto, é a Luiz Phellipe de Orleans e Bragança que ela se ligaria, porque ele preenche condições mínimas outras, não detalhadas aqui. Esse fato explicaria também a possibilidade de as manchetes jornalísticas empregarem a descrição definida para se referir ao deputado. No universo discursivo, o questionamento da legitimidade da atribuição da descrição definida não equivaleria à negação da existência da categoria a que a descrição definida faz menção no mundo real. Essa problemática é digna de inspeção, mas ultrapassa os limites pretendidos por nossa análise, que se pauta no cálculo pressuposicional da negação metalinguística.
} 
Orleans e Bragança. Assim, a descrição definida em questão deveria ficar vazia de referente e a correferenciação para o pronome ele ficaria impossibilitada. Não é o que acontece.

A sentença presente na retificação (“Ele não é príncipe”) é processada normalmente porque ele encontra um referente, já que a sentença anterior preserva a informação de que existe um indivíduo tal a quem os predicados fazer suruba gay e bater em mendigo foram atribuídos, ainda que esse indivíduo não tenha o predicado de ser príncipe.

Então, no fim do cálculo de significado desse comentário, é possível concluir que Gregório está reafirmando o boato inicial de Bebbiano, porque seu comentário diz que existe um indivíduo que não é príncipe e esse indivíduo fez suruba gay e bateu em mendigo. O que seu comentário não faz explicitamente é dizer que esse indivíduo é Luiz Phillipe de Orleans e Bragança - essa informação só é acessada indiretamente pelos falantes a partir do seu conhecimento de mundo tanto acerca do boato de Bebbiano quanto acerca da alegação do pretenso príncipe de ser um membro da (suposta) família real brasileira.

\section{CONSIDERAÇÕES FINAIS}

A cadeia argumentativa subjacente ao tweet de Gregório Duvivier é sustentada por três movimentos: (i) Bebianno entrega o dossiê a Bolsonaro, afirmando que o príncipe fez suruba gay e bateu em mendigo; (ii) Luiz Phillipe de Orleans e Bragança nega, afirmando ser falsa a afirmação de que o príncipe fez suruba gay e bateu em mendigo; (iii) por fim, Gregório reafirma o fato inicial, negando o status de príncipe do protagonista ao afirmar que é falso que o príncipe fez suruba gay e bateu mendigo. Vimos que esses movimentos são possíveis porque partem de uma afirmação inicial que contém uma descrição definida. Vimos ainda que a negação que está por trás do relato do deputado Luiz Phillipe de Orleans e Bragança é uma negação interna, de escopo estreito, que só abarca os predicados e não abarca o quantificador existencial. A negação empregada por Gregório Duvivier, por sua vez, é uma negação metalinguística, que tem escopo sobre o predicado presente na pressuposição de existência e assim afeta a aceitação completa do pressuposto da descrição definida como informação no fundo conversacional.

O dado em questão permitiu, neste artigo, uma revisitação a várias questões pertinentes a descrições definidas. A controvérsia entre Russell (1905) e Strawson (1950), que é particularmente crucial no estudo do significado, foi exposta e discutida considerando um objeto de análise objetivo e familiar para leitores de várias esferas.

Além disso, esse dado também revelou uma complexidade extra, que vem do fato de ser um dado extraído de uma interação real, não forjado. Todos os elementos lexicais, sintáticos, semânticos, pragmáticos e discursivos se apresentam aí a partir da rede de relações ativadas na situação comunicativa e é interessante mapear os limites que as análises de laboratório enfrentam. Uma questão remanescente que merece atenção é quais as consequências da negação metalinguística do predicado sobre a definitude, já que a cláusula da unicidade perde validade com a negação do predicado. Assim, o efeito de uma construção semelhante a esta, combinada com outros determinantes, especialmente indefinidos, pode levar a novas reflexões produtivas. Da mesma forma, testar a construção empregando designadores rígidos como nomes próprios pode também elucidar os limites da negação metalinguística. 


\section{REFERÊNCIAS}

BEAVER, D. I.; GEURTS, B. Presupposition. In: ZALTA, E. (Ed.) The Stanford Encyclopedia of Philosophy (Fall 2018 Edition). Disponível em: https://plato.stanford.edu/archives/ win2014/entries/presupposition/. Acesso em: 14 jul. 20.

FREGE, G. Sobre o sentido e a referência. In: FREGE, G. Lógica e Filosofia da Linguagem. São Paulo: Edusp, 2009 [1892], p. 128-158.

HORN, L. A natural history of negation. Stanford: CSLI Publications, 2001 [1989].

LEWIS, D. Scorekeeping in a Language Game. Journal of Philosophical Logic. 8:3. jun. 1979. p. 339-359.

LUDLOW, P. Descriptions. In: ZALTA, E. (Ed.) The Stanford Encyclopedia of Philosophy (Fall 2018 Edition). Disponível em: https://plato.stanford.edu/archives/fall2018/entries/ descriptions/. Acesso: 14 jul. 20.

RAPOSO, E. Orações copulativas e expressões secundárias. In: RAPOSO, E. B. P.; BACELAR DO NASCIMENTO, M. F.; MOTA, M. A. C. da; SEGURA, L.; MENDES, A. (Coord.). Gramática do Português. v. 1. Lisboa: Fund. Calouste Gulbenkian, 2013. p. 1283-135600.

RUSSELL, B. On denoting. Mind. New series, v. 14, n. 56, out. 1905. p. 479-493.

STRAWSON, P. F. On referring. Mind. New series, v. 59, n. 235, jul. 1950. p. 320-344.

SWART, H. Introduction to Natural Language Semantics. Stanford: CSLI Publications, 1998.

Recebido em: jul. 2020.

Aceito em: out. 2020. 